\title{
Studi Volume Kapasitas Air Dengan Menggunakan Single Beam Echosounder Di Area Kolam Retensi Kelurahan Air Hitam Kota Samarinda
}

\author{
Shabri Indra Suryalfihra \\ Teknologi Geomatika, Politeknik \\ Pertanian Negeri Samarinda, \\ Samarinda, 75131 \\ Shabri.indra@politanisamarinda. \\ ac.id
}

\author{
Dana Rahmadi \\ Teknologi Geomatika, Politeknik \\ Pertanian Negeri Samarinda, \\ Samarinda, 75131 \\ danarachmadi@gmail.com
}

\author{
F. V. Astrolabe Sian Prasetya* \\ Teknologi Geomatika, Politeknik \\ Pertanian Negeri Samarinda, \\ Samarinda, 75131 \\ astrolabesp@politanisamarinda.ac.id \\ *Corresponding author
}

\begin{abstract}
Abstrak - Penelitian ini dilatarbelakangi oleh berkurangnya kapasitas tampungan kolam retensi kelurahan Air Hitam yang diakibatkan akumulasi sedimen yang masuk ke dalam kolam retensi yang berakibat terjadinya perubahan pada kurva luas dan volume tampungan kolam retensi yang pada akhirnya akan mempengaruhi kemampuan pelimpah dalam mengalirkan besaran air yang datang dari drainase. Untuk dapat mengetahui volume kolam retensi tersebut harus dilakukan pengukuran kedalaman/batimetri di kolam retensi maka dilakukanlah pemeruman.

Oleh karena itu tujuan dari penelitian ini adalah untuk mengetahui volume kapasitas air di area kolam retensi kelurahan Air Hitam menggunakan Singlebeam Echosounder dengan metode pemeruman. Dari hasil penelitian ini akan disajikan dalam bentuk gambar peta batimetri dan modeling tiga dimensi, sehingga ke depan penelitian ini dapat sebagai data pendukung untuk kolam retensi kelurahan Air Hitam dapat direnovasi lagi dari segi penampungannya karena berkurangnya tampungan air diakibatkan akumulasi sedimen.

Hasil penelitian ini didapat beberapa informasi terkait dengan keadaan eksisting area kolam retensi Kelurahan Air Hitam Kota Samarinda. Pada studi volume kapasitas air pada kolam retensi Kelurahan Air Hitam didapatkan data posisi titik perum sebanyak 5.286 titik pada 17 lajur Cross Sounding dengan interval 1 detik pada tiap titiknya. Selain itu didapat informasi spasial antara lain, volume rata-rata kapasitas air adalah sebesar 122.462,513 m3, kedalaman rata-rata adalah 2,135 meter, kedalaman terdangkal adalah 1,070 meter, dan kedalaman terdalam adalah 3,420 meter.
\end{abstract}

Kata Kunci- Pemeruman, Survei Batimetri, dan Singlebeam Echosounder.

\section{PENDAhUluan}

Seiring berkembangnya zaman kegiatan manusia di wilayah perkotaan memberikan dampak positif terhadap kemajuan ekonomi penduduknya, namun disisi lain juga dapat menimbulkan permasalahan lingkungan akibat daripada pembangunan yang tidak memperhatikan daya dukung lingkungannya, masalah utama yang timbul adalah banjir. Banjir dipicu oleh kurangnya daerah resapan air atau dataran rendah, akibat banyaknya pembangunan bangunan gedung dan jalan dari peningkatan jumlah penduduk, dan kebutuhan lahan. Hal ini berdampak pada drainase sehingga air meluap dan memicu terjadinya banjir, hal inilah yang terjadi di Kelurahan Air Hitam, Kecamatan Samarinda Ulu, Kota Samarinda ini.

Kolam retensi merupakan kolam/waduk penampungan air hujan dalam jangka waktu tertentu, berfungsi untuk memotong puncak banjir yang terjadi dalam badan air/drainase. Konsep dasar dari kolam retensi adalah menampung volume air ketika debit maksimum di drainase datang, kemudian secara perlahan-lahan mengalirkan ketika debit di drainase sudah kembali normal (Dirjen Cipta Karya, 2010).

Secara alami kolam retensi akan mengalami sedimentasi dan akan terendapkan di tampungan kolam retensi karena material yang terbawa dari pengikisian dan pelapukan. Proses ini mengandalkan kekuatan aliran air, disaat aliran air kuat maka materi akan terbawa, disaat aliran air lemah maka materi akan mengendap di dasar (Dirjen SDA, 2009).

Secara bertahap kapasitas tampungan akan berkurang diakibatkan akumulasi sedimen yang masuk ke dalam kolam retensi yang berakibat terjadinya perubahan pada kurva luas dan volume tampungan kolam retensi yang pada akhirnya akan mempengaruhi kemampuan pelimpah dalam mengalirkan besaran air yang datang dari drainase. Untuk dapat mengetahui topografi permukaan dasar sedimen di kolam retensi maka dilakukanlah pemeruman dengan Echosounder. 


\section{STUdi PUSTAKA}

Studi pustaka yang berkaitan pada studi volume kapasitas air dengan menggunakan Single Beam Echosounder di area kolam retensi Kelurahan Air Hitam Kota Samarinda adalah sebagai berikut:

1. Keadaan Umum Kolam Retensi Kelurahan Air Hitam

Daerah Kelurahan Air Hitam pada Kota Samarinda telah banyak mengalami perubahan tata guna lahan, baik itu pada sungai maupun pada drainase. Perubahan yang cukup berarti ini mengakibatkan banjir pada daerah Kelurahan Air Hitam, Kecamatan Samarinda Ulu, Kota Samarinda. Mempertimbangkan hal tersebut, maka untuk mengantisipasi bahaya banjir pemerintah merencanakan kolam retensi sebagai alternatif pengendalian banjir Kelurahan Air Hitam yang dilengkapi dengan pelimpah dan pintu air (Rahmat, 2010).

Kolam retensi Kelurahan Air Hitam, Kecamatan Samarinda Ulu, Kota Samarinda sebagai kolam/waduk penampungan air pembuangan dan air hujan dari drainase, berfungsi untuk penanggulangan banjir untuk Kota Samarinda. Terdapat 3 pintu yang terbagi menjadi 2 pintu inlet dan 1 pintu outlet, masing-masing pintu tersebut memiliki fungsi sebagaimana pintu inlet 1 sebagai resapan air daratan tinggi dari arah Jl. Kadrie Oening, pintu inlet 2 sebagai air pembuangan dari arah Jl. A.W. Syahranie, dan pintu outlet sebagai alihan air apabila penampungan kolam retensi melebihi kapasitas (Rahmat, 2010).

Selain fungsi sebagai penanggulangan banjir untuk Kota Samarinda, kolam retensi tersebut juga sebagai kawasan objek wisata seperti sarana pemancingan ikan, ajang perlombaan $R C$ Boat, dan sebagai tempat usaha mikro kecil dan menengah. Terdapat beberapa gedung olahraga dikawasan kolam retensi Kelurahan Air Hitam, yaitu gedung anggar, gedung pencak silat, gedung dojang taekwondo, gedung bulu tangkis yang merupakan fasilitas atlet Kal-Tim untuk berlaga ditingkat nasional maupun lokal (Rahmat, 2010).

\section{Pemeruman (Sounding)}

Pemeruman adalah proses dan aktivitas yang ditujukan untuk memperoleh gambaran (model), bentuk permukaan (topografi), dasar perairan (seabed surface). Proses penggambaran dasar perairan tersebut (sejak pengukuran, pengolahan hingga visualisasinya) disebut sebagai survei batimetri. Gambaran dasar perairan dapat disajikan dalam garis-garis kontur dan model permukaan digital (Poerbandono dan Djunarsjah, 2005).

Garis-garis kontur kedalaman atau model batimetri diperoleh dengan menginterpolasikan titik-titik pengukuran kedalaman yang tersebar pada lokasi yang dikaji. Kerapatan titik-titik pengukuran kedalaman bergantung pada skala model yang hendak dibuat. Titiktitik pengukuran kedalaman berada pada lajur-lajur pengukuran kedalaman yang disebut sebagai lajur perum atau sounding line (Poerbandono dan Djunarsjah, 2005).

Pemeruman dilakukan dengan membuat profil (potongan) pengukuran kedalaman. Lajur perum dapat berbentuk garis-garis lurus, lingkaran-lingkaran konsentrik, atau lainnya sesuai metode yang digunakan untuk penentuan posisi titik-titik fiks perumnya. Lajurlajur perum didesain sedemikian rupa sehingga memungkinkan pendeteksian perubahan kedalaman yang lebih ekstrim. Untuk itu, desain lajur-lajur perum harus memperhatikan kecenderungan bentuk dan topografi pantai sekitar perairan yang akan disurvei. Agar mampu mendeteksi perubahan kedalaman yang lebih ekstrem lajur perum dipilih dengan arah yang tegak lurus terhadap kecenderungan arah garis pantai (Triatmodjo, 1999).

Metode pemeruman (sounding) yang digunakan pada studi ini adalah menggunakan metode akuistik. Penggunaan gelombang akustik untuk pengukuranpengukuran bawah air (termasuk: pengukuran kedalaman, arus, dan sedimen) merupakan teknik yang paling popular dalam hidrografi hingga saat ini. Untuk pengukuran kedalaman digunakan Echosounder atau perum gema, alat ini dapat dipakai untuk menghasilkan profil kedalaman yang kontinyu sepanjang jalur perum dengan ketelitian yang cukup baik (Poerbandono dan Djunarsjah, 2005).

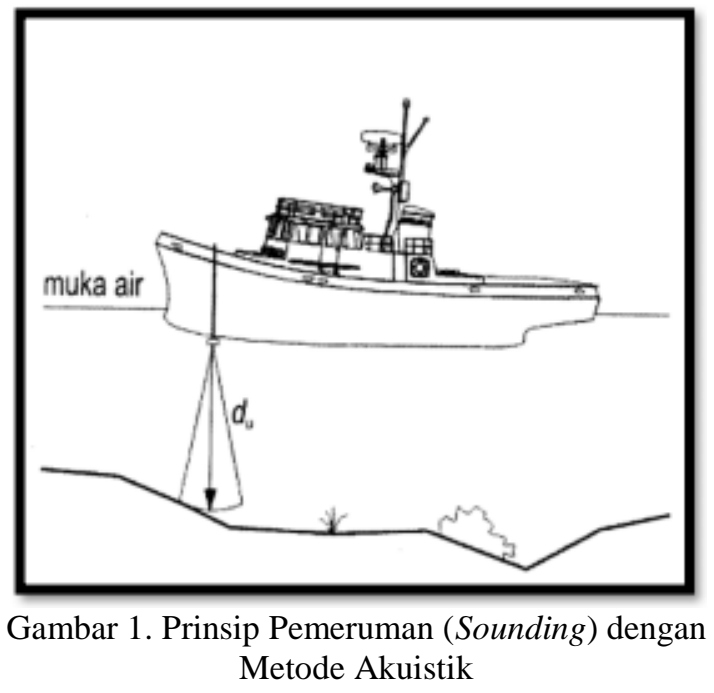

Alat perum gema menggunakan prinsip pengukuran jarak dengan memanfaatkan gelombang akustik yang dipancarkan dari Transducer. Transducer adalah bagian dari alat perum gema yang mengubah energi listrik menjadi mekanik (untuk membangkitkan gelombang suara) dan sebaliknya. Gelombang akustik tersebut merambat pada medium air dengan cepat rambat yang relatif diketahui atau dapat diprediksi hingga menyentuh dasar perairan dan dipantulkan kembali ke Transducer (Poerbandono dan Djunarsjah, 2005).

\section{Reduksi Kedalaman Air}

Hasil pengukuran pemeruman berupa kedalaman dasar air (koordinat Z), hasil ini harus dikoreksi dengan hasil muka air, serta tinggi acuan yang digunakan. (Poerbandono dan Djunasjah, 2005) 


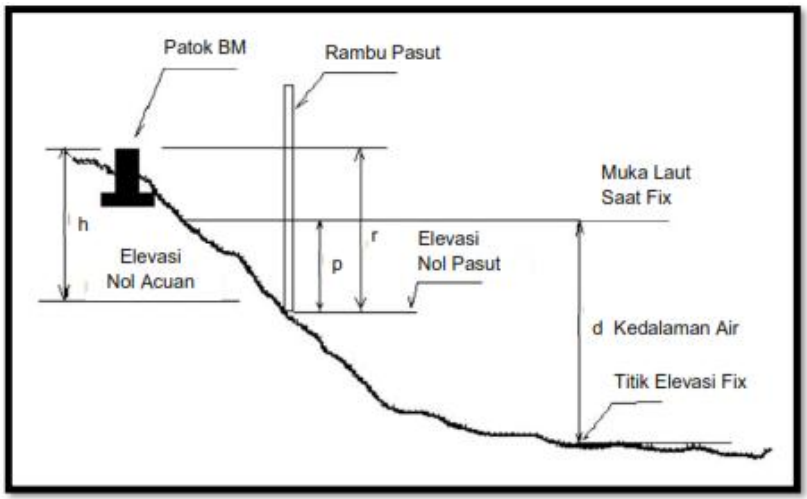

Gambar 2. Metode Reduksi Elevasi Hasil Pemeruman

Dalam proses reduksi elevasi tersebut maka hasil elevasi titik fiks dapat ditulis sebagai berikut:

$$
\text { ElevasiTitik Fix }=h-r+p-d
$$

Dimana:

$\mathrm{h}=$ Elevasi titik $\mathrm{BM}$ terhadap referensi tinggi yang dipakai (m)

$\mathrm{p}=$ Bacaan muka air sesaat $(\mathrm{m})$

$\mathrm{r}=$ Beda tinggi antara BM dengan nol pasut (m)

$\mathrm{d}=$ Kedalaman air saat penentuan posisi titik perum $(\mathrm{m})$

\section{Penentuan Posisi Titik Fiks Pemeruman dengan GPS}

Titik perum adalah titik yang menyatakan posisi perekaman data kedalaman. Ketelitian posisi titik perum pada survei dengan menggunakan Single Beam Echosounder adalah ketelitian posisi Transducer. Prinsip dasar penentuan posisi dengan GPS adalah pengukuran jarak ke beberapa satelit (yang koordinatnya telah diketahui) sekaligus, yang tidak lain merupakan kombinasi dari beberapa permukaan posisi bola konsentrik dalam ruang (Poerbandono dan Djunarsjah, 2005).

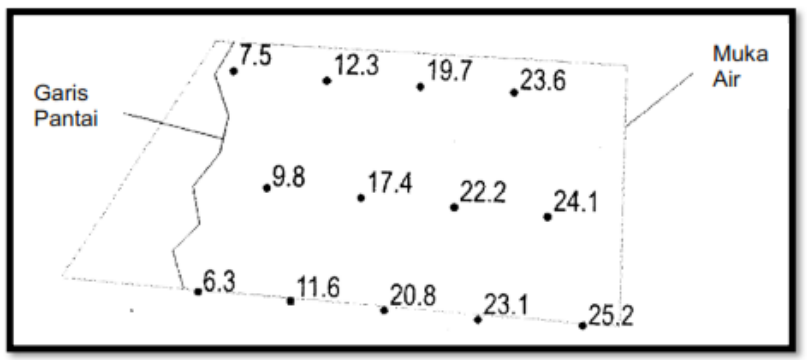

Gambar 3. Angka-angka Kedalaman pada Titik-titik Fix Pemeruman

Jarak antar titik-titik fiks perum pada suatu lajur pemeruman setidak-tidaknya sama dengan atau lebih rapat dari interval lajur perum. Saat ini, teknik perekaman data kedalaman sudah dapat dilakukan secara digital. Laju perekaman data telah mencapai yang lebih baik dari 1 titik perdetik (Poerbandono dan Djunarsjah, 2005).

\section{Single Beam Echosounder}

Single Beam Echosounder merupakan alat ukur kedalaman air yang menggunakan pancaran tunggal sebagai pengirim dan pengiriman sinyal gelombang suara. Komponen dari single beam terdiri dari transciever (transducer atau receiver) terpasang pada lambung kapal. Sistem ini mengukur kedalaman air secara langsung dari kapal penyelidikan. Transciever mengirimkan pulsa akustik dengan frekuensi tinggi yang terkandung dalam beam (gelombang suara) menyusuri bagian bawah kolom air. Energi akustik memantulkan sampai dasar laut dari kapal dan diterima kembali oleh tranciever. Transciever terdiri dari sebuah transmiter yang mempunyai fungsi sebagai pengontrol panjang gelombang pulsa yang dipancarkan dan menyediakan tenaga elektris untuk besar frekuensi yang diberikan (Urick, 1983).



Gambar 4. Single Beam Echosounder dan Multi Beam Echosounder

Prinsip kerja Single Beam Echosounder adalah pengukuran kedalaman air dengan memanfaatkan gelombang akustik. Gelombang akustik tersebut dipancarkan dari Transducer kapal secara vertikal ke dasar perairan hingga menyentuh dasar perairan dan dipantulkan kembali ke Transducer (Poerbandono dan Djunasjah, 2005). 


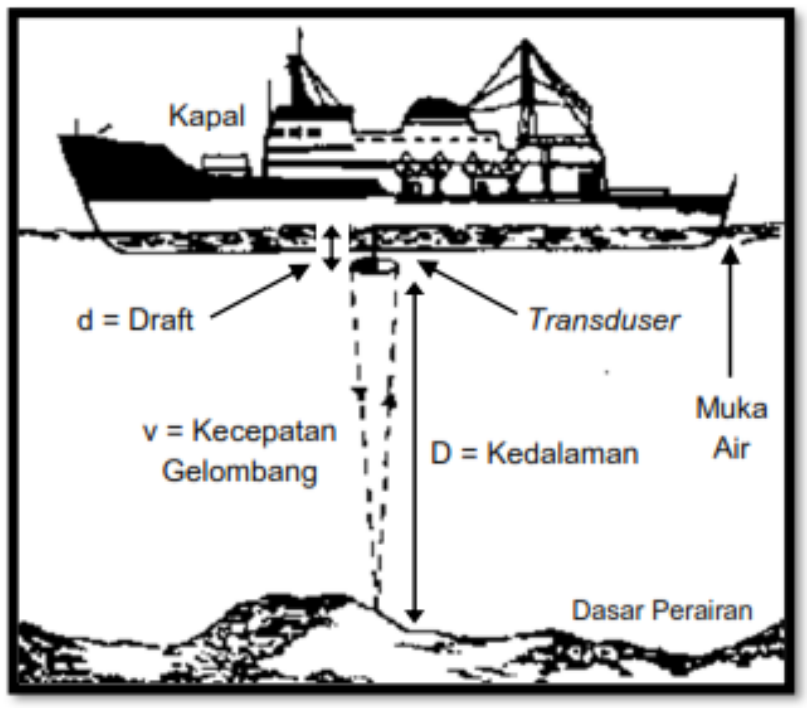

Gambar 5. Prinsip Kerja Single Beam Echosounder

Single Beam Echosounder menghitung selang waktu sejak gelombang dipancarkan dan diterima kembali $(\Delta \mathrm{t})$, sehingga jarak dasar perairan relatif terhadap Transducer adalah:

$$
D=\frac{1}{2} v \Delta t
$$

Dengan $\mathrm{D}=$ kedalaman hasil ukuran dan $\mathrm{v}=$ kecepatan gelombang akuistik pada medium air (Poerbandono dan Djunasjah, 2005).

\section{METODOLOGI}

Daerah studi volume kapasitas air ini dilaksanakan pada daerah kolam retensi Kelurahan Air Hitam, Kecamatan Samarinda Ulu, Kota Samarinda.

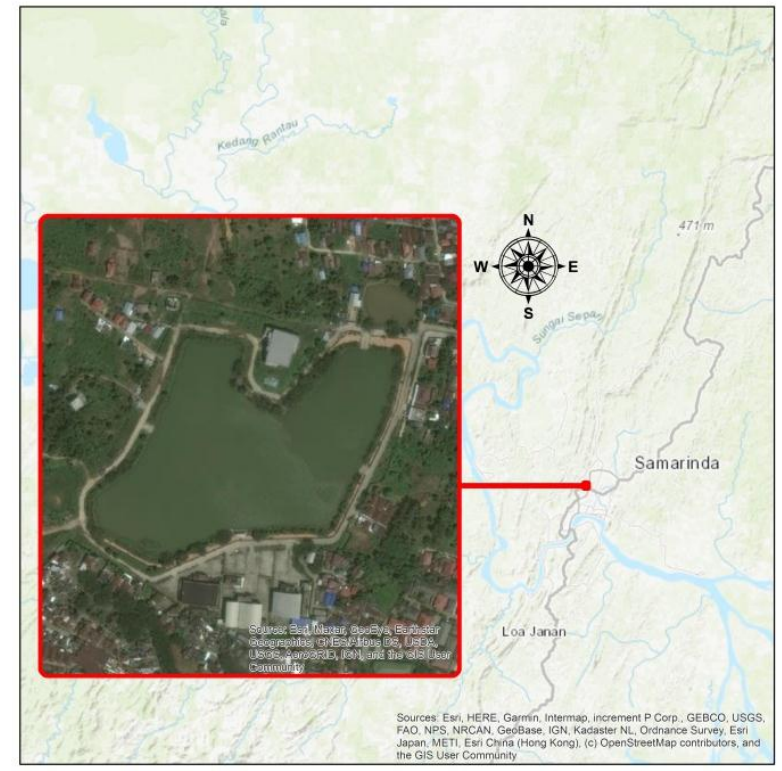

Gambar 6. Lokasi Studi Volume Kapasitas Air Kolam Retensi Kelurahan Air Hitam
Pada studi ini digunakan data lapangan, dimana dalam proses akuisisi datanya melewati beberapa tahapan pengumpulan data. Tahapan proses pengumpulan data dan proses pengolahan data akan dijelaskan pada uraian di bawah berikut.

\section{Tahap Pengambilan Data}

Pada tahap ini dilakukan pengambilan data kedalaman di kolam retensi menggunakan alat Single Beam Echosounder Hi-Target HD370. Pemeruman tersebut menggunakan kapal fiber kecil dengan mesin berkapasitas $<6$ orang. Secara bersamaan dengan pengambilan data kedalaman juga dilakukan pengambilan data posisi menggunakan alat GPS Geodetic Ashtech Promark 100 (L1). Tahap ini juga dilakukan pengambilan data situasi detail menggunakan alat Total Station, melakukan pengukuran sejangkau area Kolam Retensi Air Hitam.

Alat Single beam Echosounder Hi-Target HD370 terdiri dari head unit, pipe, cable, dan tranducer. Tranducer diletakkan di bawah kapal dan bekerja memancarkan gelombang akustik hingga menyentuh dasar perairan dan dipantulkan kembali ke Transducer. Dari cara tersebut maka akan sinyal akan diterima dan direkam pada head unit dan menghasilkan informasi kedalaman, dan untuk alat GPS Geodetic Ashtech Promark 100 (L1) terdiri dari antenna, cable, dan receiver. Antenna diletakan diatas pipe dan melakukan pengamatan posisi dari berjalannya kapal saat melakukan pemeruman.

Berikut diagram alir tahap pengambilan data ditunjukkan pada Gambar 7.

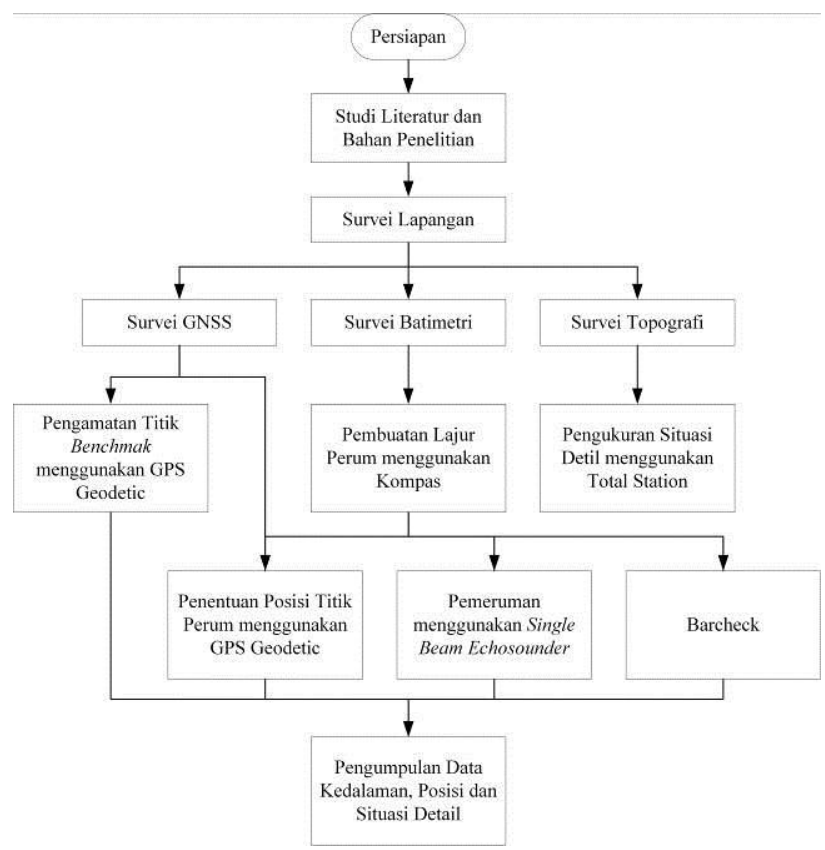

Gambar 7. Tahapan Pengambilan Data

\section{Survei Lapangan}

Sebelum memulai pengambilan data, tahap ini meliputi orientasi lapangan untuk mengetahui kondisi lapangan agar mudah saat pengambilan data. Lokasi yang 
diteliti ialah pada area kolam retensi Kelurahan Air Hitam, Kecamatan Samarinda Ulu, Kota Samarinda. Area tersebut memiliki luasan $\pm 7 \mathrm{Ha}$, yang berfungsi sebagai kolam/waduk penampungan air pembuangan dan air hujan dari drainase untuk penanggulangan banjir.

\section{Survei Batimetri}

Tahap ini merupakan tahap pengambilan data batimetri. Dalam tahap ini terdapat tiga pengukuran, yakni sebagai berikut:

1. Pembuatan Lajur Perum

Tahap ini ialah pemasangan penanda lajur perum agar mempermudah saat melakukan pemeruman sebagai acuan kapal dalam mengambil data. Tahap ini menggunakan alat kompas Suunto KB-14/360RG dan rol meter 50 meter dengan pengukuran offset metode hutang jarak dan hutang sudut. Pemasangan ini menggunakan penanda dari pita survei yang diikatkan pada batang lurus sesuai lajur perum yang diukur.

\section{Pemeruman (Sounding)}

Pada tahap ini dilakukan pemeruman untuk mendapatkan data kedalaman pada area kolam retensi kelurahan Air Hitam. Peralatan yang digunakan pada tahap ini adalah alat Single Beam Echosounder Hi-Target HD370 yang sudah dipasangkan pada kapal. Pemeruman ini dilakukan sesuai dengan lajur perum yang telah didesain. Pemeruman tersebut memerlukan barcheck sebagai kalibrasi dari alat, seperti mengecek kedalaman menggunakan rambu ukur, mengecek kedalaman draft, mengecek muka air dengan rambu ukur. Barcheck dilakukan awal sebelum pemeruman dan akhir sesudah pemeruman.

\section{Penentuan Posisi Titik Perum}

Pada tahap ini merupakan tahap bersamaan dengan tahap perum, dimana dilakukan agar data kedalaman yang diambil akan dikontrol dengan data posisi horizontal. Penentuan posisi titik perum ini menggunakan GPS Geodetic Ashtech Promark 100 (L1) dengan metode Continous Kinematic.

\section{Survei GNSS}

Tahap ini merupakan proses penentuan koordinat pada titik benchmark yang sebagai titik acuan untuk semua pekerjaan. Pengamatan titik benchmark ini menggunakan GPS Geodetic Ashtech Promark 100 (L1) dengan metode Static Differential. Tahap ini mengamati 4 titik benchmark, titik tersebut terbuat dari kayu ulin dengan ukuran $10 \mathrm{~cm}$ x $10 \mathrm{~cm}$ x $50 \mathrm{~cm}$ yang diletakkan pada utara, timur, selatan, dan barat di pinggiran area kolam retensi Air Hitam.

\section{Survei Topografi}

Tahap pengambilan data situasi detail yang berada pada area kolam retensi Air Hitam, dilakukan dengan menggunakan alat Total Station Nikon NPL-632 dengan sistem poligon terbuka dimana pengukuran tersebut telah diikatkan pada titik benchmark yang telah diketahui koordinatnya setelah dilakukan pengamatan titik benchmark. Pengukuran situasi detail ini mendapatkan gambaran tentang kondisi area yang dipetakan, yang meliputi batas pagar, posisi bangunan, jalan, dan yang lainnya.

Tahap Pengolahan Data

Dalam tahap ini dilakukan pengolahan data di perangkat lunak Microsoft Excel 2016 untuk menggabungkan data kedalaman dan data posisi horizontal sesuai waktu yang direkam. Menginput data yang telah digabungkan berupa data posisi horizontal (X dan Y) dan juga data kedalaman (D) pada perangkat lunak Autocad Civil 3D Land Desktop Companion 2009. Data yang digunakan dalam penelitian ini adalah data primer yang diperoleh secara langsung di lapangan berupa data kedalaman, data posisi titik perum, data pengamatan titik benchmark dan data situasi detail. Berikut diagram alir tahap pengolahan data ditunjukkan pada Gambar 8 .

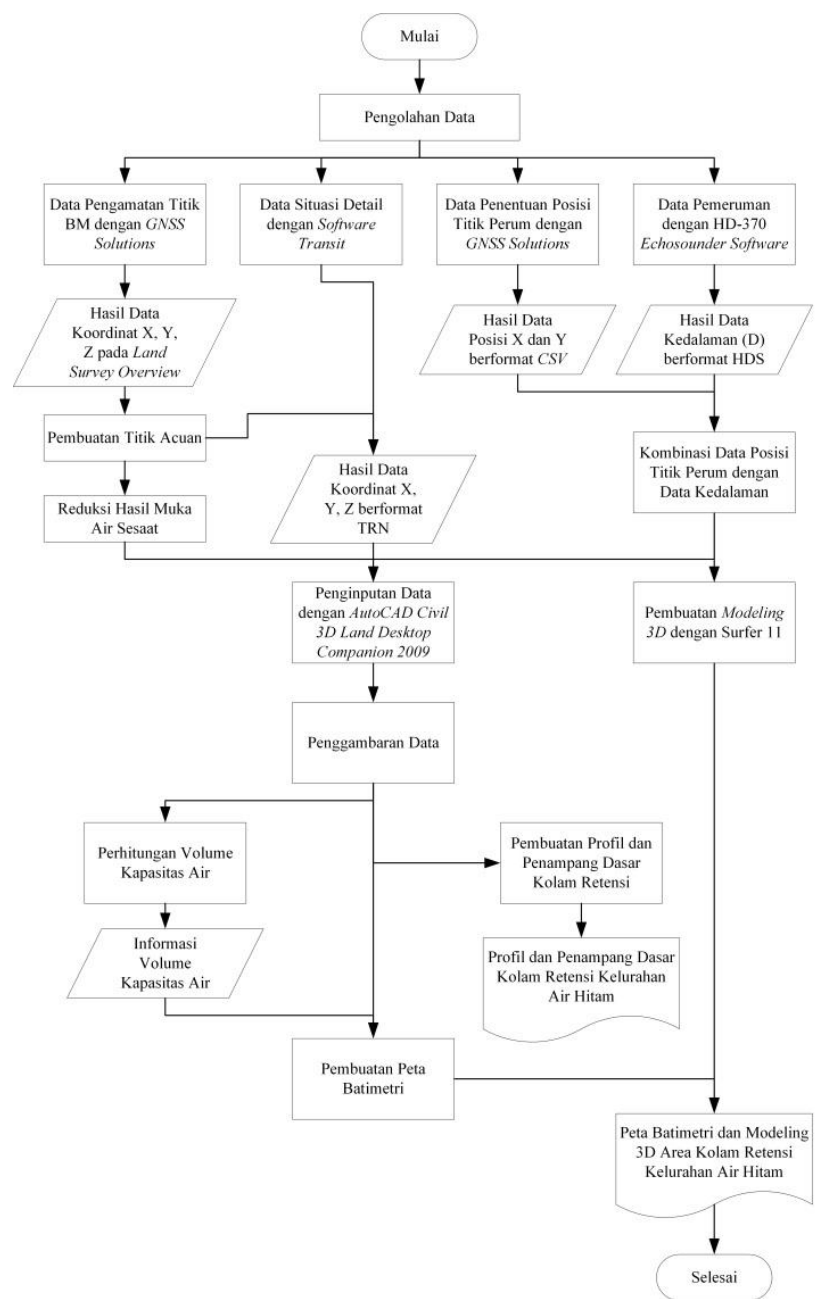

Gambar 8. Tahapan Pengolahan Data

\section{HASIL DAN PEMBAHASAN}

\section{Hasil Pengamatan Titik Benchmark}

Data titik benchmark diperoleh dari pengamatan GPS Geodetic Promark 100 (L1) dengan metode Static Differential, dimana titik benchmark merupakan titik acuan pada pengukuran situasi detail dan acuan reduksi muka air sesaat. Hasil yang diperoleh dari pengamatan titik benchmark adalah data koordinat titik benchmark 
beserta Report Land Survey Overview, dimana report tersebut digunakan untuk melihat ketelitian dari hasil pengolahan data pengamatan titik benchmark tersebut. Ketelitian yang didapat adalah sebesar $1 \mathrm{~mm}$ dari 4 titik benchmark yang telah dilakukan proses pengolahan. Hasil dari pengamatan titik benchmark yang diperoleh dapat dilihat pada tabel 1 berikut.

Tabel 1. Hasil Data Koordinat Titik Benchmark

\begin{tabular}{cccc}
\hline \multirow{2}{*}{ Nama Tugu } & \multicolumn{3}{c}{ Koordinat $(\mathrm{m})$} \\
\cline { 2 - 4 } & Easting & Northing & Elevasi \\
\hline BM Utara & $515.123,175$ & $9.948 .250,016$ & 67,385 \\
BM Selatan & $515.126,997$ & $9.948 .059,689$ & 66,484 \\
BM Timur & $515.270,549$ & $9.948 .187,747$ & 67,379 \\
BM Barat & $514.930,745$ & $9.948 .164,925$ & 67,435 \\
\hline Sumber : hasil pengukuran lapangan
\end{tabular}

\section{Hasil Pemeruman}

Data kedalaman diperoleh dari kegiatan pemeruman yang berkonsentrasi pada kolam retensi, hasil data kedalaman berupa jarak dalam air dari muka air sampai ke permukaan sedimen yang diukur menggunakan Single Beam Echosounder Hi-Target HD370. Data yang diperoleh dapat dilihat pada lampiran, sebagai contoh data yang diperoleh ialah sebagai berikut:

Tabel 2. Contoh Data Kedalaman pada Lajur Cross Sounding menggunakan Single Beam Echosounder Hi-Target HD370

\begin{tabular}{ccccc}
\hline $\begin{array}{c}\text { Point } \\
\text { No. }\end{array}$ & Time & $\begin{array}{c}\text { Depths } \\
(\mathrm{m})\end{array}$ & $\begin{array}{c}\text { Draft } \\
(\mathrm{m})\end{array}$ & $\begin{array}{c}\text { Sound } \\
\text { Velocity } \\
(\mathrm{m} / \mathrm{s})\end{array}$ \\
\hline 842 & $10: 30: 46$ & 1,44 & 0,6 & 1500 \\
843 & $10: 30: 50$ & 1,14 & 0,6 & 1500 \\
844 & $10: 30: 55$ & 1,07 & 0,6 & 1500 \\
845 & $10: 31: 00$ & 1,17 & 0,6 & 1500 \\
846 & $10: 31: 05$ & 1,49 & 0,6 & 1500 \\
847 & $10: 31: 10$ & 1,57 & 0,6 & 1500 \\
848 & $10: 31: 15$ & 1,56 & 0,6 & 1500 \\
849 & $10: 31: 20$ & 1,52 & 0,6 & 1500 \\
850 & $10: 31: 25$ & 1,52 & 0,6 & 1500 \\
851 & $10: 31: 30$ & 1,54 & 0,6 & 1500 \\
852 & $10: 31: 35$ & 1,54 & 0,6 & 1500 \\
853 & $10: 31: 40$ & 1,3 & 0,6 & 1500 \\
854 & $10: 31: 45$ & 1,3 & 0,6 & 1500 \\
855 & $10: 31: 50$ & 1,3 & 0,6 & 1500 \\
856 & $10: 31: 55$ & 1,38 & 0,6 & 1500 \\
857 & $10: 32: 00$ & 1,38 & 0,6 & 1500 \\
\hline Sumber: hasilpengukuran lapangan & &
\end{tabular}

Data posisi titik fiks perum diperoleh dari pengamatan posisi titik perum yang diukur menggunakan GPS Geodetic Ashtech Promark 100 (L1) dengan metode Continous Kinematik Absolute. Hasil yang didapatkan berupa posisi titik fiks perum dari berjalannya kapal saat melakukan kegiatan pemeruman. Pengamatan posisi titik perum dilakukan selama berjalannya kegiatan pemeruman. Data yang diperoleh dapat dilihat pada lampiran, sebagai contoh data yang diperoleh seperti pada tabel 3 berikut.
Tabel 3. Contoh Data Posisi Titik Fiks Perum pada Lajur Cross Sounding menggunakan Single Beam Echosounder Hi-Target HD370

\begin{tabular}{cccccccc}
\hline Id & Desc & $\mathrm{X}(\mathrm{m})$ & $\mathrm{Y}(\mathrm{m})$ & $\mathrm{Z}(\mathrm{m})$ & $\mathrm{h}$ & $\mathrm{m}$ & $\mathrm{s}$ \\
\hline 1 & CS & 515070,360 & 9948070,739 & 57,692 & 2 & 24 & 41 \\
2 & CS & 515070,358 & 9948070,750 & 57,697 & 2 & 24 & 42 \\
3 & CS & 515070,360 & 9948070,791 & 57,710 & 2 & 24 & 43 \\
4 & CS & 515070,366 & 9948070,815 & 57,717 & 2 & 24 & 44 \\
5 & CS & 515070,380 & 9948070,833 & 57,720 & 2 & 24 & 45 \\
6 & CS & 515070,384 & 9948070,844 & 57,725 & 2 & 24 & 46 \\
7 & CS & 515070,380 & 9948070,846 & 57,730 & 2 & 24 & 47 \\
8 & CS & 515070,386 & 9948070,839 & 57,737 & 2 & 24 & 48 \\
9 & CS & 515070,390 & 9948070,830 & 57,744 & 2 & 24 & 49 \\
10 & CS & 515070,397 & 9948070,832 & 57,748 & 2 & 24 & 50 \\
\hline \multicolumn{7}{l}{ Sumber : hasil pengukuran lapangan }
\end{tabular}

Hasil pemeruman yang dilakukan di area kolam retensi kelurahan Air Hitam Kecamatan Samarinda Ulu Kota Samarinda, adalah sebagai berikut:

a. Terdapat sebanyak 582 titik kedalaman pada 17 lajur Cross Sounding yang terekam dengan interval 5 detik tiap titiknya.

b. Terdapat sebanyak 5.286 titik posisi titik fiks perum pada 17 lajur Cross Sounding yang terekam dengan interval 1 detik tiap titiknya.

c. Kedalaman rata-rata di area kolam retensi Kelurahan Air Hitam adalah 2.135 meter

d. Kedalaman di area kolam retensi Kelurahan Air Hitam terdangkal adalah 1,07 meter

e. Kedalaman di area kolam retensi Kelurahan Air Hitam terdalam adalah 3,07 meter

\section{Hasil Reduksi Muka Air Sesaat}

Hasil pengukuran pemeruman berupa kedalaman dasar air. Kedalaman tersebut adalah jarak antara muka air dengan seabed surface sehingga hasil ini harus dikoreksi dengan hasil muka air dengan acuan datum yang digunakan sebagai acuan. Pengkoreksian hasil tersebut dapat dilihat pada skema contoh perhitungan sebagai berikut:

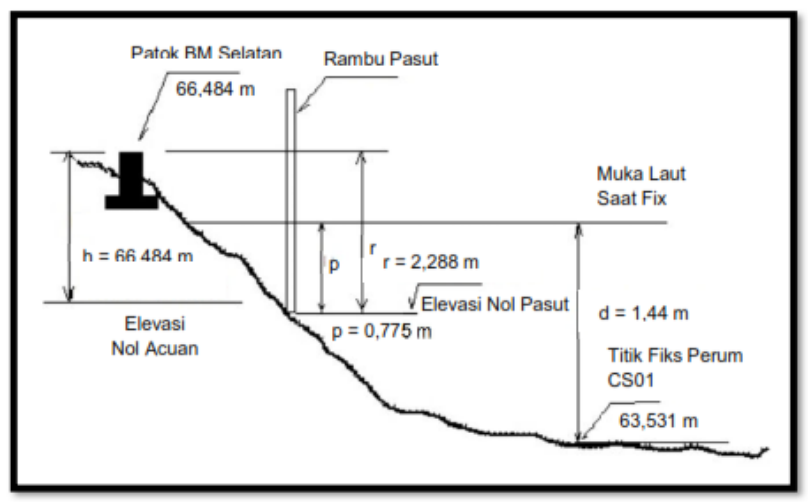

Gambar 9. Skema Perhitungan Reduksi Muka Air Sesaat

4. Hasil Pengukuran Situasi Detail

Hasil pengukuran situasi detail yang dilakukan di area kolam retensi Kelurahan Air Hitam Kecamatan Samarinda Ulu Kota Samarinda adalah terdapat sebanyak 1.314 titik situasi detail yang diukur. Berikut adalah gambaran situasi detail yang didapat dari hasil pengukuran. 


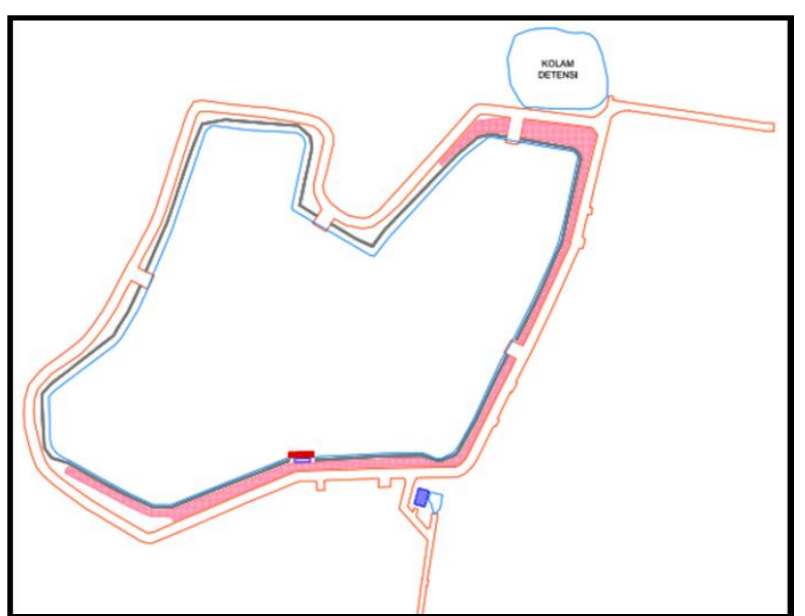

Gambar 10. Situasi Detail Area Kolam Retensi Air Hitam

\section{Hasil Volume Kapasitas Air}

Hasil data yang telah diolah tersebut mendapatkan informasi volume dari kapasitas air di area kolam retensi kelurahan Air Hitam dengan menggunakan AutoCAD Civil 3D Land Desktop Companion 2009. Volume tersebut dihitung secara otomatis dengan metode yang berbeda untuk menghasilkan informasi volume yang akurat, ada 4 cara untuk menghitung volume tersebut dengan metode grid, composite, prismoidal, average end area yang ditunjukkan pada tabel 4 berikut:

Tabel 4. Volume Kapasitas Air di Area Kolam Retensi Kelurahan Air Hitam

\begin{tabular}{cccc}
\hline No & $\begin{array}{c}\text { Elevasi Muka } \\
\text { Air Sesaat } \\
(\mathrm{m})\end{array}$ & Metode & $\begin{array}{c}\text { Volume } \\
\left(\mathrm{m}^{3}\right)\end{array}$ \\
\hline 1. & & Grid & $122.421,455$ \\
2. & 64,971 & Composite & $122.477,595$ \\
3. & Average End Area & $122.477,000$ \\
4. & \multicolumn{2}{c}{ Prismoidal } & $122.474,000$ \\
\multicolumn{3}{c}{ Rata-rata } \\
\hline
\end{tabular}

\section{Hasil Peta Batimetri}

Dengan data yang telah ada, disajikan dalam bentuk peta batimetri dengan informasi kedalaman di area kolam retensi kelurahan Air Hitam. Layout peta dengan ukuran kertas A3, menggunakan AutoCAD Civil 3D Land Desktop Companion 2009. Peta batimetri area kolam retensi kelurahan Air Hitam dapat dilihat pada Gambar 11.

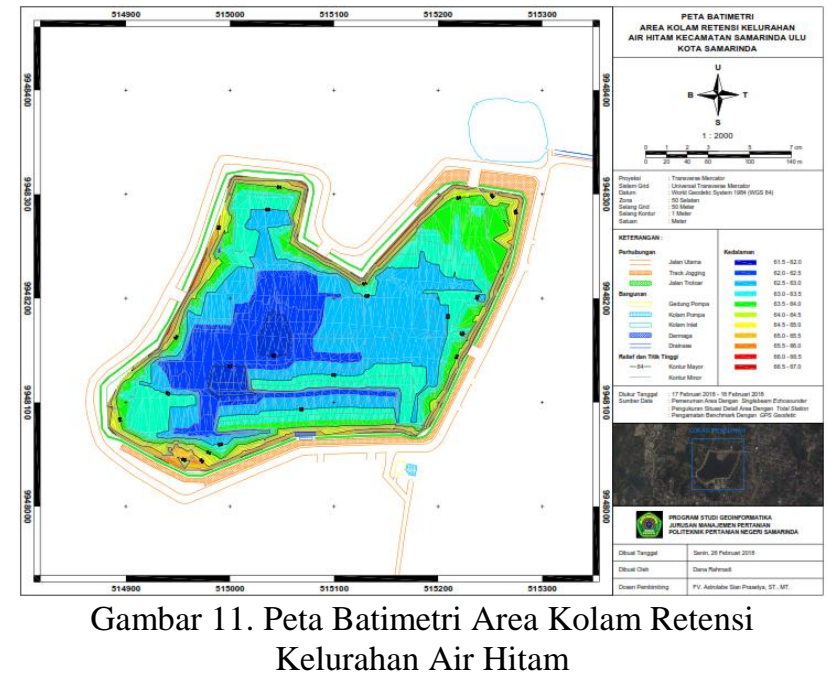

7. Hasil Profil

Kedalaman pada area kolam retensi Kelurahan Air Hitam disajikan sebanyak 15 profil dengan interval 25 meter pada setiap profilnya.

\section{Hasil Penampang}

Kedalaman pada area kolam retensi Kelurahan Air Hitam disajikan sebanyak 11 penampang melintang dengan interval 25 meter pada setiap penampangnya.

\section{Hasil 3D Modeling}

Visualiasi dari hasil penelitian disajikan dalam bentuk berupa $3 D$ Modeling menggunakan, berikut ini adalah contoh gambar $3 D$ Modeling dari hasil pemeruman yang dilakukan ditunjukkan pada Gambar 12 berikut.

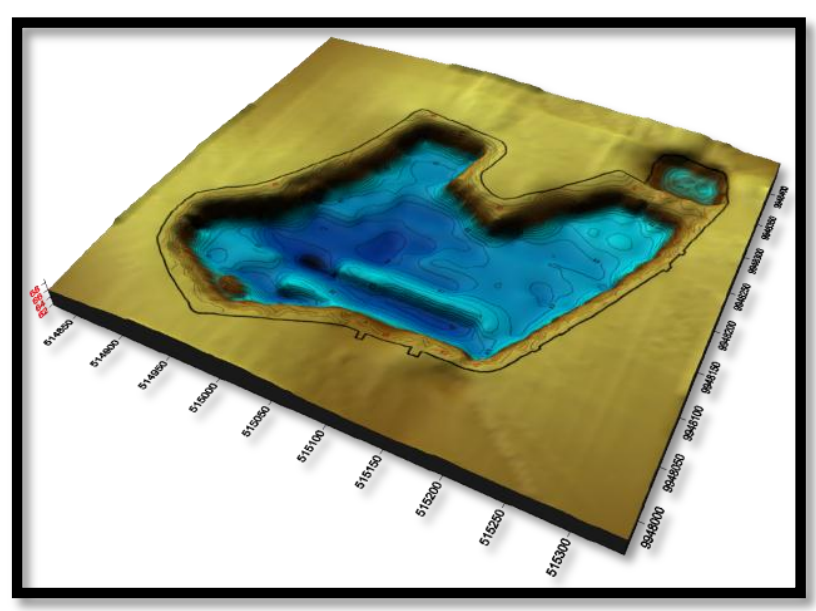

Gambar 12. 3D Modeling Area Kolam Retensi Kelurahan Air Hitam

\section{Pembahasan}

Volume yang telah dihitung merupakan ruang dari kapasitas air kolam retensi Kelurahan Air Hitam, yang dimana ruang tersebut hasil dari perhitungan antara seabed dasar kolam retensi Kelurahan Air Hitam dengan surface muka air normal pada waktu saat itu, perhitungan tersebut menggunakan perangkat lunak AutoCAD Civil $3 D$ Land Desktop Companion 2009 secara otomatis 
dengan metode yang digunakan ialah metode Grid, metode Composite, metode Average End Area dan metode Prismoidal. Metode Grid merupakan interpolasi volume yang menggunakan grid dengan melapisi pada kedua permukaan TIN (Triangulation Irregular Network), sedangkan metode Average End Area dan Prismoidal merupakan metode section dengan menginterpolasikan potongan melintang dari kedua permukaan TIN (Triangulation Irregular Network). Dari hasil perhitungan volume kapasitas air tersebut menghasilkan besaran volume yang telah dirata-ratakan dari keempat metode tersebut sebesar 122.462,513 meter kubik.

Dari hasil reduksi muka air sesaat yang diperoleh yaitu titik benchmark yang digunakan sebagai titik acuan ialah BM_SELATAN yang merupakan titik benchmark terdekat dengan palem pasut pada dermaga, titik benchmark BM_SELATAN menggunakan datum World Geodetic System (WGS) 1984 dengan nilai elevasi 66,484 $\mathrm{m}$, bacaan muka air sesaat adalah $0,775 \mathrm{~m}$ yang dibaca pada palem waktu pemeruman berlangsung tidak terjadi pasang surut karena air dalam keadaan normal, beda tinggi antara BM_SELATAN dengan nol pasut pada palem adalah $2,288 \mathrm{~m}$, dari hasil reduksi tersebut juga dapat diketahui bahwa elevasi muka air sesaat pada waktu pemeruman adalah 64,971 m. Dari hasil pengukuran situasi detail yang diperoleh dapat diketahui bahwa luasan area pemeruman pada kolam retensi Kelurahan Air Hitam adalah 6,8531694 ha.

\section{KESIMPULAN}

Besarnya volume rata-rata kapasitas air pada area kolam retensi Kelurahan Air Hitam yang didapatkan dari hasil pemeruman adalah sebesar $122.462,513 \mathrm{~m}^{3}$ pada elevasi muka air normal.Dari hasil pemeruman area kolam retensi Kelurahan Air Hitam mendapatkan 2 lajur perum yaitu Long Sounding dan Cross Sounding. Terdapat sebanyak 582 titik kedalaman pada 17 lajur Cross Sounding dengan interval 5 detik ditiap titiknya.

Hasil pemeruman di area kolam retensi Kelurahan Air Hitam mendapatkan nilai kedalaman rata-rata sebesar 2,135 meter, kedalaman terdangkal sebesar 1,070 meter dan kedalaman terdalam sebesar 3,420 meter.Dari hasil penentuan posisi titik perum di area kolam retensi Kelurahan Air Hitam mendapatkan sebanyak 5.286 titik posisi titik fiks perum pada 17 lajur Cross Sounding dengan interval 1 detik ditiap titiknya.

\section{DAFTAR PUSTAKA}

Abidin, H. Z. 2002. Survei dengan GPS. Jakarta: Institut Teknologi Bandung.

Adhi I. K. 2016. Pemetaan Metode Terestris untuk Pembuatan Peta Situasi Skala 1:500 Dusun Serang Desa Sendangsari Kecamatan Pengasih Kabupaten Kulonprogo Provinsi Daerah Istimewah Yogyakarta. Yogyakarta: Teknik Geomatika Universitas Gajah Mada.

Adiyuwono N. S. 1995. Teknik Membaca Peta dan Kompas. Angkasa.
Anonim. 2013. Echosounder atau Perum Gema https://marineinside.wordpress.com. (diakses pada tanggal 12 Oktober 2017).

Ashtech. 2010. GNSS Solutions Reference Manual.

Burdic W. S. 1991. Underwater Acoustic System Analysis. New Jersey: Prentice Hall.

Dirjen Cipta Karya. 2010. Tata Cara Pembuatan Kolam Retensi dan Polder. Jakarta: Departemen Pekerjaan Umum.

Dirjen SDA. 2009. Pedoman Survei dan Monitoring Sedimentasi Waduk. Jakarta: Balai Keamanan Bendungan.

Djunarsjah E. 2001. Standar Survei (Baru) dalam Survei Hidrografi (SP-44 IHO tahun 1998). Surabaya.

Djunarsjah E. 2007. Catatan Kuliah Hidrografi II. Bandung: Teknik Geodesi Institut Teknologi Bandung. Golden Software, Inc. 2002. Surfer 8 User Guide.

Hi-Target Surveying Instrument Co., Ltd. 2010. HD370/380/390 Echosounder Operation Manual.

Kavanagh B.F. and Glenn Bird S.J. 1996. Surveying Principles and Applications. Edisi 4. Prentice Hall.

KK Hidrografi. 2007. Pekerjaan Pengumpulan Data Hidrografi, Oseanografi, dan Geofisika Untuk Rencana Pemasangan Kabel Bawah Laut di Selat Sunda. Proposal Teknis. Bandung: Teknik Geodesi Institut Teknologi Bandung.

Kurland K. S. 2008. AutoCAD 2009 2D Training Manual. Parkinson B.W. 1996. Echosounder : Theory and Applications, Chapter 1 : Introduction and Heritage of NAVSTAR, the Global Positioning System. PP. 3-28. Washington, D.C.: American Institute of Aeronautics and Astronautics.

Poerbandono dan Djunarsjah E. 2005. Survei Hidrografi. Bandung: Refika Aditama.

Purwaamijaya I. M. 2008. Teknik Survei dan Pemetaan. Jilid 3. Bandung: Direktorat Pembinaan Sekolah Menengah Kejuruan.

Rahmat A. 2010. Banjir Samarinda. Samarinda.

Safi' A. F. 2015. Survei Sistem Satelit Navigasi Global. Surabaya: Teknik Geomatika Institut Teknologi Sepuluh Nopember Surabaya.

SNI 7646:2010. 2010. Survei Hidrografi Menggunakan Singlebeam Echosounder. Jakarta: Badan Standardisasi Nasional.

Triatmodjo B. 1999. Teknik Pantai. Yogyakarta: FT. TGM.

Urick R. J. 1983. Principles of Underwater Sound. Edisi 3. New York: McGraw-Hill Book Company.

UU No 26 Tahun 2007. Penataan Ruang. 